\title{
Flow towards a Stagnation Region of a Vertical Plate in a Hybrid Nanofluid: Assisting and Opposing Flows
}

\author{
Iskandar Waini ${ }^{1,2}$, Anuar Ishak $2, *(1)$ and Ioan Pop ${ }^{3}$ \\ 1 Fakulti Teknologi Kejuruteraan Mekanikal dan Pembuatan, Universiti Teknikal Malaysia Melaka, Hang Tuah \\ Jaya, Durian Tunggal, Melaka 76100, Malaysia; iskandarwaini@utem.edu.my \\ 2 Department of Mathematical Sciences, Faculty of Science and Technology, Universiti Kebangsaan Malaysia, \\ Bangi, Selangor 43600, Malaysia \\ 3 Department of Mathematics, Babeş-Bolyai University, 400084 Cluj-Napoca, Romania; ipop@math.ubbcluj.ro \\ * Correspondence: anuar_mi@ukm.edu.my
}

check for updates

Citation: Waini, I.; Ishak, A.; Pop, I. Flow towards a Stagnation Region of a Vertical Plate in a Hybrid Nanofluid: Assisting and Opposing Flows. Mathematics 2021, 9, 448. https:// doi.org/10.3390/math9040448

Academic Editor: Eva H. Dulf

Received: 4 February 2021

Accepted: 20 February 2021

Published: 23 February 2021

Publisher's Note: MDPI stays neutral with regard to jurisdictional claims in published maps and institutional affiliations.

Copyright: (c) 2021 by the authors. Licensee MDPI, Basel, Switzerland. This article is an open access article distributed under the terms and conditions of the Creative Commons Attribution (CC BY) license (https:/ / creativecommons.org/licenses/by/ $4.0 /)$.

\begin{abstract}
This study investigates a hybrid nanofluid flow towards a stagnation region of a vertical plate with radiation effects. The hybrid nanofluid consists of copper $(\mathrm{Cu})$ and alumina $\left(\mathrm{Al}_{2} \mathrm{O}_{3}\right)$ nanoparticles which are added into water to form $\mathrm{Cu}-\mathrm{Al}_{2} \mathrm{O}_{3} /$ water nanofluid. The stagnation point flow describes the fluid motion in the stagnation region of a solid surface. In this study, both buoyancy assisting and opposing flows are considered. The similarity equations are obtained using a similarity transformation and numerical results are obtained via the boundary value problem solver (bvp4c) in MATLAB software. Findings discovered that dual solutions exist for both opposing and assisting flows. The heat transfer rate is intensified with the thermal radiation $(49.63 \%)$ and the hybrid nanoparticles (32.37\%).
\end{abstract}

Keywords: hybrid nanofluid; dual solutions; mixed convection; stagnation point; radiation; stability analysis

\section{Introduction}

The phenomenon of the flow on a stagnation region commonly occurs in aerodynamic industries and engineering applications. To name a few, such applications are polymer extrusion, drawing of plastic sheets, and wire drawing. Hiemenz [1] was the first researcher to consider the boundary layer flow toward a stagnation point on a rigid surface. Besides this, the axisymmetric flow was considered by Homann [2], whereas the oblique stagnationpoint flow was studied by Chiam [3]. Further, Merkin [4] studied a similar problem by considering the mixed convection flow. He discovered that the solution is not unique for the opposing flow case. However, Ishak et al. [5] exposed that the dual solutions exist for both opposing and assisting flows, and these behaviours were also reported by several researchers [6-9].

In 1995, Choi and Eastman [10] presented a new type of heat transfer fluid called nanofluid, which is a mixture of single type nanoparticles and the base fluid, to enhance the thermal conductivity. Some works on such fluids can be found in [11-16]. Recently, some studies have shown that advanced nanofluids composed of other types of nanoparticles mixed with regular nanofluids could improve their thermal properties, and this mixture is termed "hybrid nanofluid". The earlier experimental works on the hybrid nanofluid have been done by Turcu et al. [17], Jana et al. [18], and Suresh et al. [19]. Besides, the numerical studies on the hybrid nanofluid flow were studied by Devi and Devi [20]. They observed that the heat transfer rate of the hybrid nanofluid is higher than that of the regular nanofluid. Moreover, the non-uniqueness of the solutions in the hybrid nanofluid flow was examined by Waini et al. [21-27] Other physical aspects were considered by several authors [28-35]. Furthermore, the review papers can be found in [36-41]. 
Different from the above-mentioned studies, this paper considers the assisting and opposing buoyant flows of a hybrid nanofluid containing $\mathrm{Al}_{2} \mathrm{O}_{3}-\mathrm{Cu}$ hybrid nanoparticles when the effect of thermal radiation is taken into consideration. The governing equations along with the boundary conditions are transformed into a system of ordinary differential equations using a similarity transformation. The system of equations is then solved numerically using the boundary value problem solver (bvp4c) in MATLAB software. Most importantly, in this study, two solutions are discovered for both opposing and assisting flows. Then, further analysis is performed to study the temporal stability of these solutions as time evolves.

\section{Mathematical Formulation}

Consider the flow configuration as shown in Figure 1. The free stream velocity is $U(x)=a x$ and the surface temperature is $T_{w}(x)=T_{\infty}+b x$, where $a$ and $b$ are constants. Meanwhile, the ambient temperature $T_{\infty}$ is assumed to be constant. Accordingly, the hybrid nanofluid equations are as follows $([5,14])$ :

$$
\begin{gathered}
\frac{\partial u}{\partial x}+\frac{\partial v}{\partial y}=0 \\
u \frac{\partial u}{\partial x}+v \frac{\partial u}{\partial y}=U \frac{d U}{d x}+\frac{\mu_{h n f}}{\rho_{h n f}} \frac{\partial^{2} u}{\partial y^{2}}+\frac{(\rho \beta)_{h n f}}{\rho_{h n f}}\left(T-T_{\infty}\right) g \\
u \frac{\partial T}{\partial x}+v \frac{\partial T}{\partial y}=\frac{k_{h n f}}{\left(\rho C_{p}\right)_{h n f}} \frac{\partial^{2} T}{\partial y^{2}}-\frac{1}{\left(\rho C_{p}\right)_{h n f}} \frac{\partial q_{r}}{\partial y}
\end{gathered}
$$

subject to

$$
\begin{gathered}
v=0, \quad u=0, \quad T=T_{w}(x)=T_{\infty}+b x \quad \text { at } \quad y=0 \\
u \rightarrow U(x)=a x, \quad T \rightarrow T_{\infty} \quad \text { as } \quad y \rightarrow \infty
\end{gathered}
$$

where $u$ and $v$ represent the velocity components along the $x$ - and $y$-axes. Besides, $g$ and $q_{r}$ are the acceleration caused by the gravity and the radiative heat flux, respectively. Meanwhile, the temperature of the hybrid nanofluid is given by $T$.

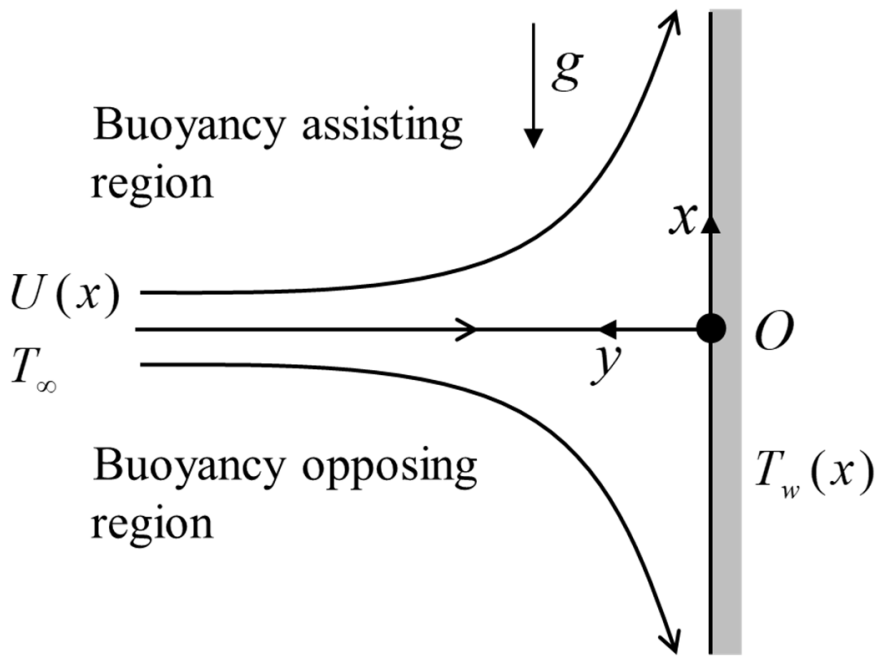

Figure 1. The flow configuration.

The expression of the radiative heat flux is $([42,43])$ :

$$
q_{r}=-\frac{4 \sigma^{*}}{3 k^{*}} \frac{\partial T^{4}}{\partial y}
$$


where $\sigma^{*}$ and $k^{*}$ denote the Stefan-Boltzmann constant and the mean absorption coefficient, respectively. Following Rosseland [42], after employing a Taylor series, one gets $T^{4} \cong 4 T_{\infty}^{3} T-3 T_{\infty}^{4}$. Then, the Equation (3) turns to [43]:

$$
u \frac{\partial T}{\partial x}+v \frac{\partial T}{\partial y}=\frac{1}{\left(\rho C_{p}\right)_{h n f}}\left[k_{h n f}+\frac{16 \sigma^{*} T_{\infty}^{3}}{3 k^{*}}\right] \frac{\partial^{2} T}{\partial y^{2}}
$$

Further, the thermophysical properties can be referred to in Tables 1 and 2. Data from these tables are adapted from Oztop and Abu-Nada [13], Devi and Devi [20], and Waini et al. [21]. Note that $\varphi_{1}\left(\mathrm{Al}_{2} \mathrm{O}_{3}\right)$ and $\varphi_{2}(\mathrm{Cu})$ are the nanoparticles volume fractions, and the subscripts $n 1$ and $n 2$ are corresponded to their solid components, while the subscripts $f, n f$, and $h n f$ signify the base fluid, nanofluid, and hybrid nanofluid, respectively.

To get a similarity solution, we employ the following similarity transformation $([5,14])$ :

$$
\psi=\sqrt{a v_{f}} x f(\eta), \quad \theta(\eta)=\frac{T-T_{\infty}}{T_{w}-T_{\infty}}, \quad \eta=y \sqrt{\frac{a}{v_{f}}}
$$

where $\psi$ is the stream function defined as $u=\partial \psi / \partial y$ and $v=-\partial \psi / \partial x$, then one gets

$$
u=a x f^{\prime}(\eta), \quad v=-\sqrt{a v_{f}} f(\eta)
$$

Table 1. Thermophysical properties of nanoparticles and water.

\begin{tabular}{|c|c|c|}
\hline Properties & Nanofluid & Hybrid Nanofluid \\
\hline $\begin{array}{l}\text { Dynamic } \\
\text { viscosity }\end{array}$ & $\mu_{n f}=\frac{\mu_{f}}{\left(1-\varphi_{1}\right)^{2.5}}$ & $\mu_{h n f}=\frac{\mu_{f}}{\left(1-\varphi_{1}\right)^{2.5}\left(1-\varphi_{2}\right)^{2.5}}$ \\
\hline Density & $\rho_{n f}=\left(1-\varphi_{1}\right) \rho_{f}+\varphi_{1} \rho_{n 1}$ & $\rho_{h n f}=\left(1-\varphi_{2}\right)\left[\left(1-\varphi_{1}\right) \rho_{f}+\varphi_{1} \rho_{n 1}\right]+\varphi_{2} \rho_{n 2}$ \\
\hline $\begin{array}{l}\text { Thermal } \\
\text { expansion }\end{array}$ & $(\rho \beta)_{n f}=\left(1-\varphi_{1}\right)(\rho \beta)_{f}+\varphi_{1}(\rho \beta)_{n 1}$ & $(\rho \beta)_{h n f}=\left(1-\varphi_{2}\right)\left[\left(1-\varphi_{1}\right)(\rho \beta)_{f}+\varphi_{1}(\rho \beta)_{n 1}\right]+\varphi_{2}(\rho \beta)_{n 2}$ \\
\hline Heat capacity & $\begin{array}{c}\left(\rho C_{p}\right)_{n f}= \\
\left(1-\varphi_{1}\right)\left(\rho C_{p}\right)_{f}+\varphi_{1}\left(\rho C_{p}\right)_{n 1}\end{array}$ & $\left(\rho C_{p}\right)_{h n f}=\left(1-\varphi_{2}\right)\left[\left(1-\varphi_{1}\right)\left(\rho C_{p}\right)_{f}+\varphi_{1}\left(\rho C_{p}\right)_{n 1}\right]+\varphi_{2}\left(\rho C_{p}\right)_{n 2}$ \\
\hline $\begin{array}{l}\text { Thermal } \\
\text { conductivity }\end{array}$ & $\frac{k_{n f}}{k_{f}}=\frac{k_{n 1}+2 k_{f}-2 \varphi_{1}\left(k_{f}-k_{n 1}\right)}{k_{n 1}+2 k_{f}+\varphi_{1}\left(k_{f}-k_{n 1}\right)}$ & $\begin{aligned} \frac{k_{h n f}}{k_{n f}} & =\frac{k_{n 2}+2 k_{n f}-2 \varphi_{2}\left(k_{n f}-k_{n 2}\right)}{k_{n 2}+2 k_{n f}+\varphi_{2}\left(k_{n f}-k_{n 2}\right)} \\
& \text { where } \\
\frac{k_{n f}}{k_{f}} & =\frac{k_{n 1}+2 k_{f}-2 \varphi_{1}\left(k_{f}-k_{n 1}\right)}{k_{n 1}+2 k_{f}+\varphi_{1}\left(k_{f}-k_{n 1}\right)}\end{aligned}$ \\
\hline
\end{tabular}

\begin{tabular}{cccc}
\hline \multirow{2}{*}{ Properties } & Base Fluid & \multicolumn{2}{c}{ Nanoparticles } \\
\cline { 2 - 4 } & Water & $\mathbf{A l}_{2} \mathbf{O}_{3}$ & $\mathbf{C u}$ \\
\hline$\rho\left(\mathrm{kg} / \mathrm{m}^{3}\right)$ & 997.1 & 3970 & 8933 \\
$\beta \times 10^{-5}(1 / \mathrm{K})$ & 21 & 0.85 & 1.67 \\
$C_{p}(\mathrm{~J} / \mathrm{kgK})$ & 4179 & 765 & 385 \\
$k(\mathrm{~W} / \mathrm{mK})$ & 0.613 & 40 & 400 \\
Prandtl number, $\mathrm{Pr}$ & 6.2 & & \\
\hline
\end{tabular}

Table 2. Thermophysical properties of nanofluid and hybrid nanofluid.

Furthermore, the continuity equation, i.e., Equation (1), is identically satisfied. Now, Equations (2) and (6) respectively reduce to:

$$
\frac{\mu_{h n f} / \mu_{f}}{\rho_{h n f} / \rho_{f}} f^{\prime \prime \prime}+f f^{\prime \prime}-f^{\prime 2}+1+\frac{(\rho \beta)_{h n f} /(\rho \beta)_{f}}{\rho_{h n f} / \rho_{f}} \lambda \theta=0
$$




$$
\frac{1}{\operatorname{Pr}} \frac{1}{\left(\rho C_{p}\right)_{h n f} /\left(\rho C_{p}\right)_{f}}\left(\frac{k_{h n f}}{k_{f}}+\frac{4}{3} R\right) \theta^{\prime \prime}+f \theta^{\prime}-f^{\prime} \theta=0
$$

subject to the boundary conditions:

$$
\begin{gathered}
f(0)=0, \quad f^{\prime}(0)=0, \quad \theta(0)=1, \\
f^{\prime}(\infty)=1, \quad \theta(\infty)=0
\end{gathered}
$$

where $\left({ }^{\prime}\right)$ represents the differentiation with respect to $\eta, \operatorname{Pr}$ is the Prandtl number, $R$ and $\lambda$ signify the radiation and the mixed convection parameters, given by:

$$
\operatorname{Pr}=\frac{\left(\mu C_{p}\right)_{f}}{k_{f}}, \quad R=\frac{4 \sigma^{*} T_{\infty}^{3}}{k^{*} k_{f}}, \quad \lambda=\frac{g \beta_{f} b}{a^{2}}=\frac{G r_{x}}{R e_{x}^{2}}
$$

Further, $G r_{x}=g \beta_{f}\left(T_{w}-T_{\infty}\right) x^{3} / v_{f}^{2}$ corresponds to the local Grashof number and $R e_{x}=a x^{2} / v_{f}$ stands for the local Reynold's number. Note that $\lambda<0$ signifies the opposing and $\lambda>0$ signifies the assisting flows, while the forced convection flow (no buoyancy effects) is given by $\lambda=0$.

The skin friction coefficient $C_{f}$ and the local Nusselt number $N u_{x}$ are defined as [43]:

$$
C_{f}=\frac{\mu_{h n f}}{\rho_{f} U^{2}}\left(\frac{\partial u}{\partial y}\right)_{y=0}, \quad N u_{x}=\frac{x}{k_{f}\left(T_{w}-T_{\infty}\right)}\left(-k_{h n f}\left(\frac{\partial T}{\partial y}\right)_{y=0}+\left(q_{r}\right)_{y=0}\right)
$$

By employing Equation (7), one gets:

$$
R e_{x}^{1 / 2} C_{f}=\frac{\mu_{h n f}}{\mu_{f}} f^{\prime \prime}(0), R e_{x}^{-1 / 2} N u_{x}=-\left(\frac{k_{h n f}}{k_{f}}+\frac{4}{3} R\right) \theta^{\prime}(0)
$$

\section{Stability Analysis}

The temporal stability of the dual solutions as time evolves is studied. This analysis was first introduced by Merkin [44] and then followed by Weidman et al. [45] Firstly, consider the new variables as follows:

$$
\psi=\sqrt{a v_{f}} x f(\eta, \tau), \quad \theta(\eta, \tau)=\frac{T-T_{\infty}}{T_{w}-T_{\infty}}, \quad \eta=y \sqrt{\frac{a}{v_{f}}}, \tau=a t
$$

Now, the unsteady form of Equations (2) and (3) are considered, while Equation (1) remains unchanged. On using (15), one obtains:

$$
\begin{gathered}
\frac{\mu_{h n f} / \mu_{f}}{\rho_{h n f} / \rho_{f}} \frac{\partial^{3} f}{\partial \eta^{3}}+f \frac{\partial^{2} f}{\partial \eta^{2}}-\left(\frac{\partial f}{\partial \eta}\right)^{2}+1+\frac{(\rho \beta)_{h n f} /(\rho \beta)_{f}}{\rho_{h n f} / \rho_{f}} \lambda \theta-\frac{\partial^{2} f}{\partial \eta \partial \tau}=0 \\
\frac{1}{\operatorname{Pr}} \frac{1}{\left(\rho C_{p}\right)_{h n f} /\left(\rho C_{p}\right)_{f}}\left(\frac{k_{h n f}}{k_{f}}+\frac{4}{3} R\right) \frac{\partial^{2} \theta}{\partial \eta^{2}}+f \frac{\partial \theta}{\partial \eta}-\frac{\partial f}{\partial \eta} \theta-\frac{\partial \theta}{\partial \tau}=0
\end{gathered}
$$

subject to:

$$
\begin{gathered}
f(0, \tau)=0, \quad \frac{\partial f}{\partial \eta}(0, \tau)=0, \quad \theta(0, \tau)=1, \\
\frac{\partial f}{\partial \eta}(\infty, \tau)=1, \quad \theta(\infty, \tau)=0
\end{gathered}
$$

Then, consider the following perturbation functions [45]:

$$
f(\eta, \tau)=f_{0}(\eta)+e^{-\gamma \tau} F(\eta), \quad \theta(\eta, \tau)=\theta_{0}(\eta)+e^{-\gamma \tau} G(\eta)
$$

Here, Equation (19) is introduced to apply a small disturbance on the steady solution $f=f_{0}(\eta)$ and $\theta=\theta_{0}(\eta)$ of Equations (9)-(11). The functions $F(\eta)$ and $G(\eta)$ in 
Equation (19) are relatively small compared to $f_{0}(\eta)$ and $\theta_{0}(\eta)$. The sign (positive or negative) of the eigenvalue $\gamma$ determines the stability of the solutions. By employing (19), Equations (16)-(18) become:

$$
\begin{gathered}
\frac{\mu_{h n f} / \mu_{f}}{\rho_{h n f} / \rho_{f}} F^{\prime \prime \prime}+f_{0} F^{\prime \prime}+f_{0}^{\prime \prime} F-2 f_{0}^{\prime} F^{\prime}+\frac{(\rho \beta)_{h n f} /(\rho \beta)_{f}}{\rho_{h n f} / \rho_{f}} \lambda G+\gamma F^{\prime}=0 \\
\frac{1}{\operatorname{Pr}} \frac{1}{\left(\rho C_{p}\right)_{h n f} /\left(\rho C_{p}\right)_{f}}\left(\frac{k_{h n f}}{k_{f}}+\frac{4}{3} R\right) G^{\prime \prime}+f_{0} G^{\prime}+\theta_{0}^{\prime} F-f_{0}^{\prime} G-\theta_{0} F^{\prime}+\gamma G=0
\end{gathered}
$$

subject to:

$$
\begin{gathered}
F(0)=0, \quad F^{\prime}(0)=0, \quad G(0)=0, \\
F^{\prime}(\infty)=0, \quad G(\infty)=0
\end{gathered}
$$

Without loss of generality we set $F^{\prime \prime}(0)=1$ [46] to get the eigenvalues $\gamma$ in Equations (20) and (21). The stability of the solutions as time evolves is determined by examining the values of the smallest eigenvalue that was obtained. As time passes, there is an initial decay of disturbance if $\gamma$ is positive (see Equation (19)), and thus the solution is stable and physically reliable in the long run. On the other hand, if $\gamma$ is negative, there is an initial growth of disturbance, hence the solution is unstable.

\section{Results and Discussion}

Equations (9)-(11) were solved numerically by utilising the boundary value problem solver (bvp4c) in MATLAB software, which employs the 3-stage Lobatto IIIa formula [47]. This is a collocation formula and provides a continuous solution with fourth-order accuracy. The effectiveness of this solver ultimately counts on our ability to provide the algorithm with an initial guess for the solution. Moreover, the suitable value of the boundary layer thickness must be chosen depending on the values of the parameters applied. To solve this boundary value problem, it is necessary to first reduce the equations to a system of first-order ordinary differential equations. The effects of the physical parameters such as $\mathrm{Al}_{2} \mathrm{O}_{3}\left(\varphi_{1}\right)$ and $\mathrm{Cu}\left(\varphi_{2}\right)$ nanoparticles volume fractions, the Prandtl number Pr, the radiation parameter $R$, and the mixed convection parameter $\lambda$ on the flow behaviour are examined.

The values of the skin friction coefficient $f^{\prime \prime}(0)$ and the local Nusselt number $-\theta^{\prime}(0)$ for several values of $\operatorname{Pr}$ when $R=0, \lambda=1$, and $\varphi_{1}=\varphi_{2}=0$ (regular fluid) are compared with published results of Ishak et al. [5], as presented in Table 3. It should be mentioned that Ishak et al. [5] solved their problem by the Keller-box method. Meanwhile, the boundary value problem solver (bvp4c) is employed in this study. It is found that the results are in excellent agreement. This gives confidence to the validity and accuracy of the numerical results for other values of parameters. Besides, the values of $f^{\prime \prime}(0)$ show a decreasing behaviour, while the values of $-\theta^{\prime}(0)$ increase for larger Pr. Additionally, Table 4 describes the values of $R e_{x}^{1 / 2} C_{f}$ and $R e_{x}^{-1 / 2} N u_{x}$ for $\mathrm{Cu}$ / water nanofluid when $\varphi_{1}=R=0$ and $\operatorname{Pr}=6.2$ with different values of $\lambda$ and $\varphi_{2}$. Here, we note that the values of both $\operatorname{Re}_{x}^{1 / 2} C_{f}$ and $R e_{x}^{-1 / 2} N u_{x}$ increase with the increasing of $\lambda$ and $\varphi_{2}$. Besides, dual solutions are found for opposing $(\lambda=-1)$ and assisting $(\lambda=1)$ flows, whereas the unique solution is obtained for $\lambda=0$ (force convection flow). Furthermore, the values of $\operatorname{Re}_{x}^{1 / 2} C_{f}$ for $\lambda=0$ provided in the same table are compared with those of Bachok et al. [14], and the results are in excellent agreement, which thus gives confidence to the results for other values of $\lambda$. 
Table 3. Values of $f^{\prime \prime}(0)$ and $-\theta^{\prime}(0)$ for different values of $\operatorname{Pr}$ when $\varphi_{1}=\varphi_{2}=0$ (regular fluid), $R=0$, and $\lambda=1$.

\begin{tabular}{ccccc}
\hline \multirow{2}{*}{ Pr. } & \multicolumn{2}{c}{$f^{\prime \prime}(\mathbf{0})$} & \multicolumn{2}{c}{$-\boldsymbol{\theta}^{\prime}(\mathbf{0})$} \\
\cline { 2 - 5 } & Ishak et al. [5] & Present Results & Ishak et al. [5] & Present Results \\
\hline 0.7 & $1.7063[1.2387]$ & $1.70632[1.23873]$ & $0.7641[1.0226]$ & $0.76406[1.02263]$ \\
1 & $1.6754[1.1332]$ & $1.67544[1.13319]$ & $0.8708[1.1691]$ & $0.87078[1.16913]$ \\
6.2 & & $1.52677[0.61317]$ & & $1.65242[2.13399]$ \\
7 & $1.5179[0.5824]$ & $1.51791[0.58240]$ & $1.7224[2.2192]$ & $1.72238[2.21919]$ \\
10 & $1.4928[0.4958]$ & $1.49284[0.49578]$ & $1.9446[2.4940]$ & $1.94462[2.49403]$ \\
20 & $1.4485[0.3436]$ & $1.44848[0.34364]$ & $2.4576[3.1646]$ & $2.45759[3.16461]$ \\
\hline
\end{tabular}

Results in "[ ]" are the lower branch (second) solutions.

Table 4. Values of $R e_{x}^{1 / 2} C_{f}$ and $R e_{x}^{-1 / 2} N u_{x}$ for $\mathrm{Cu}$ /water nanofluid when $\varphi_{1}=R=0$ and $\operatorname{Pr}=6.2$ under various values of $\lambda$ and $\varphi_{2}$.

\begin{tabular}{ccccc}
\hline \multirow{2}{*}{$\lambda$} & \multirow{2}{*}{$\varphi_{2}$} & \multicolumn{2}{c}{$\boldsymbol{R} \boldsymbol{e}_{x}^{1 / 2} C_{f}$} & $\boldsymbol{R} \boldsymbol{e}_{x}^{-1 / 2} N u_{x}$ \\
\cline { 3 - 5 } & & Bachok et al. [14] & Present Results & Present Results \\
\hline \multirow{2}{*}{-1} & 0.1 & & $1.5811[-0.1602]$ & $1.8967[-2.3965]$ \\
& 0.2 & & $2.3161[0.1908]$ & $2.2872[-3.8078]$ \\
\hline \multirow{2}{*}{0} & 0.1 & 1.8843 & 1.8843 & 1.9692 \\
& 0.2 & 2.6226 & 2.6227 & 2.3494 \\
\hline \multirow{2}{*}{1} & 0.1 & & $2.1725[0.8884]$ & $2.0336[3.7324]$ \\
& 0.2 & & $2.9183[1.2445]$ & $2.4064[5.7802]$ \\
\hline
\end{tabular}

Results in "[ ]" are the lower branch (second) solutions.

Moreover, Table 5 shows the effect of $\lambda, R$ and $\varphi_{2}$ on $R e_{x}^{1 / 2} C_{f}$ and $R e_{x}^{-1 / 2} N u_{x}$ when $\operatorname{Pr}=6.2$ for nanofluid $\left(\mathrm{Cu} /\right.$ water) and hybrid nanofluid $\left(\mathrm{Cu}-\mathrm{Al}_{2} \mathrm{O}_{3} /\right.$ water). For the first solutions, we found that the values of $\operatorname{Re}_{x}^{1 / 2} C_{f}$ are accelerated with the increasing of $\lambda$ and $\varphi_{2}$; however, they are decelerated with $R$. Besides, the values of $R e_{x}^{-1 / 2} N u_{x}$ enhance with increasing values of these parameters. The local Nusselt number $R e_{x}^{-1 / 2} N u_{x}$ enhance up to $32.37 \%$ for $\mathrm{Cu}-\mathrm{Al}_{2} \mathrm{O}_{3} /$ water $\left(\varphi_{1}=0.1, \varphi_{2}=0.04\right)$ compared to the regular fluid $\left(\varphi_{1}=\varphi_{2}=0\right)$ when $\lambda=-1, R=0$, and $\operatorname{Pr}=6.2$. Meanwhile, the values of $R e_{x}^{-1 / 2} N u_{x}$ are prominent for larger radiation $(R=1)$ with $49.63 \%$ enhancement compared to the non-radiant case $(R=0)$ when $\lambda=-1, \varphi_{1}=0.1, \varphi_{2}=0.04$, and $\operatorname{Pr}=6.2$. Moreover, the rise in $\lambda$ from -1 to 1 contributes to the increment in the values of $R e_{x}^{-1 / 2} N u_{x}$ up to $8.66 \%$ when $R=1, \varphi_{1}=0.1, \varphi_{2}=0.04$, and $\operatorname{Pr}=6.2$.

Table 5. Values of $R e_{x}^{1 / 2} C_{f}$ and $R e_{x}^{-1 / 2} N u_{x}$ when $\operatorname{Pr}=6.2$ for different physical parameters.

\begin{tabular}{|c|c|c|c|c|c|c|}
\hline \multirow{2}{*}{$\lambda$} & \multirow{2}{*}{$R$} & \multirow{2}{*}{$\varphi_{2}$} & \multicolumn{2}{|c|}{$\mathrm{Cu} /$ Water $\left(\varphi_{1}=0\right)$} & \multicolumn{2}{|c|}{$\mathrm{Cu}-\mathrm{Al}_{2} \mathrm{O}_{3} /$ Water $\left(\varphi_{1}=0.1\right)$} \\
\hline & & & $\boldsymbol{R e}_{x}^{1 / 2} C_{f}$ & $R e_{x}^{-1 / 2} N u_{x}$ & $\boldsymbol{R e}_{x}^{1 / 2} C_{f}$ & $\boldsymbol{R} \boldsymbol{e}_{x}^{-1 / 2} \boldsymbol{N} u_{x}$ \\
\hline \multirow{6}{*}{-1} & \multirow{3}{*}{0} & 0 & $0.9131[-0.3719]$ & $1.4779[-1.1835]$ & $1.2896[-0.3019]$ & $1.7766[-1.8984]$ \\
\hline & & 0.02 & $1.0475[-0.3432]$ & $1.5672[-1.4219]$ & $1.4271[-0.2546]$ & $1.8673[-2.1625]$ \\
\hline & & 0.04 & $1.1801[-0.3071]$ & $1.6528[-1.6605]$ & $1.5656[-0.2008]$ & $1.9563[-2.4313]$ \\
\hline & \multirow{3}{*}{1} & 0 & $0.8342[-0.3440]$ & $2.5034[-1.5160]$ & $1.2300[-0.2235]$ & $2.7541[-2.3870]$ \\
\hline & & 0.02 & $0.9755[-0.2936]$ & $2.6044[-1.8351]$ & $1.3717[-0.1513]$ & $2.8430[-2.6909]$ \\
\hline & & 0.04 & $1.1136[-0.2334]$ & $2.6950[-2.1359]$ & $1.5137[-0.0716]$ & $2.9272[-2.9891]$ \\
\hline \multirow{6}{*}{1} & \multirow{3}{*}{0} & 0 & $1.5268[0.6132]$ & $1.6524[2.1340]$ & $1.8958[0.7439]$ & $1.9328[3.0137]$ \\
\hline & & 0.02 & $1.6524[0.6617]$ & $1.7309[2.4197]$ & $2.0304[0.8031]$ & $2.0173[3.3718]$ \\
\hline & & 0.04 & $1.7789[0.7136]$ & $1.8079[2.7224]$ & $2.1675[0.8656]$ & $2.1010[3.7485]$ \\
\hline & \multirow{3}{*}{1} & 0 & $1.5928[0.8445]$ & $2.8771[3.7973]$ & $1.9481[0.9837]$ & $3.0441[4.7696]$ \\
\hline & & 0.02 & $1.7140[0.9041]$ & $2.9422[4.1738]$ & $2.0797[1.0510]$ & $3.1132[5.2068]$ \\
\hline & & 0.04 & $1.8367[0.9661]$ & $3.0043[4.5633]$ & $2.2140[1.1210]$ & 3.1807 [5.6584] \\
\hline
\end{tabular}


The variations of the skin friction coefficient $R e_{x}^{1 / 2} C_{f}$ and the local Nusselt number $R e_{x}^{-1 / 2} N u_{x}$ against $\lambda$ for several values of $\varphi_{2}$ and $R$ are illustrated in Figures 2-5. The dual solutions of Equations (9)-(11) are possible for both assisting $(\lambda>0)$ and opposing $(\lambda<0)$ flows. The flow is accelerated for $\lambda>0$ because there is a favourable pressure gradient induced by the buoyancy forces, which results in larger heat transfer and skin friction coefficients rather than the case of $\lambda=0$ (non-buoyant case). We note that the separation of the boundary layer occurs when $\lambda<0$. The dual solutions happen for $\lambda>\lambda_{c}$ and no solution for $\lambda<\lambda_{c}$. The curve terminates at $\lambda=\lambda_{c}$ (critical value) and this point is known as the bifurcation point of the solutions. Separately, Figures 2 and 3 display the variations of $\operatorname{Re}_{x}^{1 / 2} C_{f}$ and $R e_{x}^{-1 / 2} N u_{x}$ against $\lambda$ for different values of $\varphi_{2}$ when $\operatorname{Pr}=6.2$ and $\varphi_{1}=0.1$ in the absence of $R$. It is observed that the values of $\operatorname{Re}_{x}^{1 / 2} C_{f}$ and $R e_{x}^{-1 / 2} N u_{x}$ enhance with the rising of $\varphi_{2}$. Moreover, it is noticed that the boundary layer separation is delayed with the added hybrid nanoparticles. The critical values are $\lambda_{c}=-4.6983,-5.1215$, and -5.5404 for $\varphi_{2}=0,0.02$ and 0.04 , respectively. Apart from that, the variations of $R e_{x}^{1 / 2} C_{f}$ and $R e_{x}^{-1 / 2} N u_{x}$ with $\lambda$ for different values of $R$ when $\operatorname{Pr}=6.2, \varphi_{1}=0.1$, and $\varphi_{2}=0.04$ are illustrated in Figures 4 and 5 . In the presence of $R$, we found that the skin friction coefficient $R e_{x}^{1 / 2} C_{f}$ decreases for $\lambda<0$ but increases for $\lambda>0$, whereas the local Nusselt number $R e_{x}^{-1 / 2} N u_{x}$ enhances for both cases. Besides, we notice that the domain of $\lambda$ for the existence of the dual solutions decreases for larger values of $R$ where the critical values of $\lambda$ slightly increase. Note that the critical values $\lambda_{c}$ for $R=0,1$, and 2 are $\lambda_{c}=-5.5404$, -4.7843 , and -4.4030 , respectively. It is observed in Figures 3 and 5 , the second solutions of $R e_{x}^{-1 / 2} N u_{x}$ are boundless as $\lambda \rightarrow 0^{-}$and as $\lambda \rightarrow 0^{+}$.

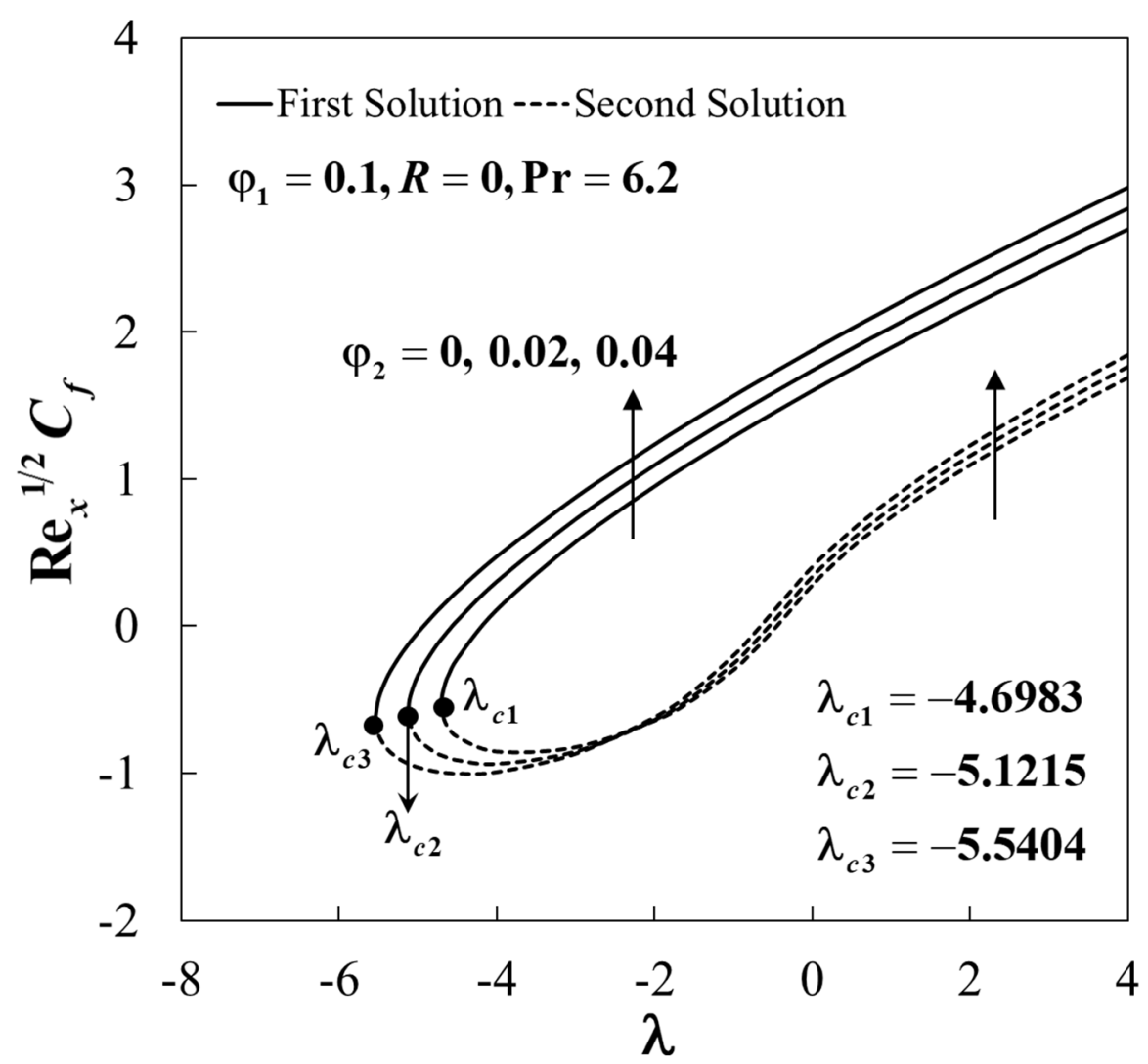

Figure 2. The variations of the skin friction coefficient $\operatorname{Re}_{x}^{1 / 2} C_{f}$ against the mixed convection parameter $\lambda$ for different values of the $\mathrm{Cu}$ nanoparticle volume fractions $\varphi_{2}$. 


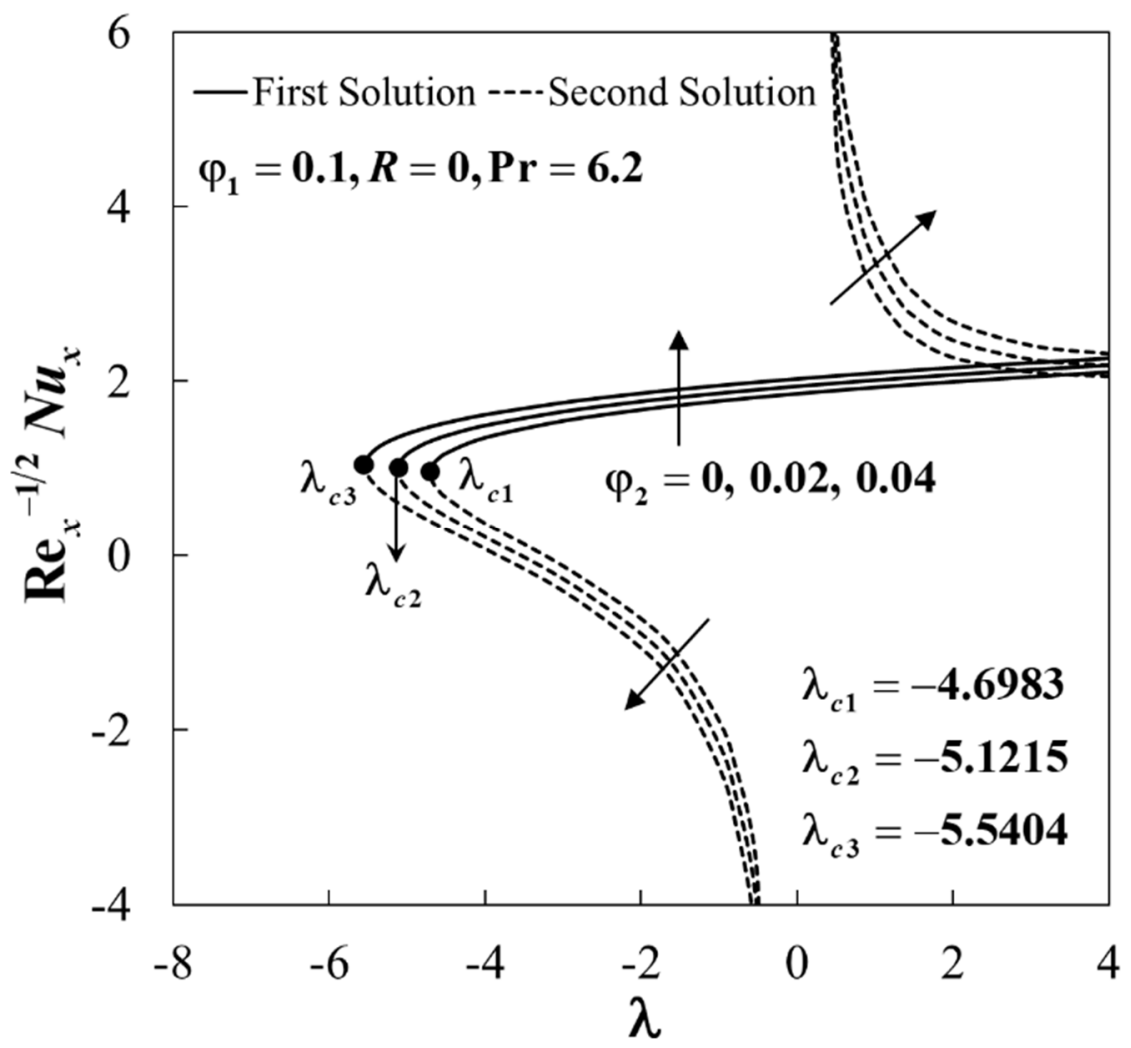

Figure 3. The variations of the local Nusselt number $R e_{x}^{-1 / 2} N u_{x}$ against the mixed convection parameter $\lambda$ for different values of the $\mathrm{Cu}$ nanoparticles volume fractions $\varphi_{2}$.

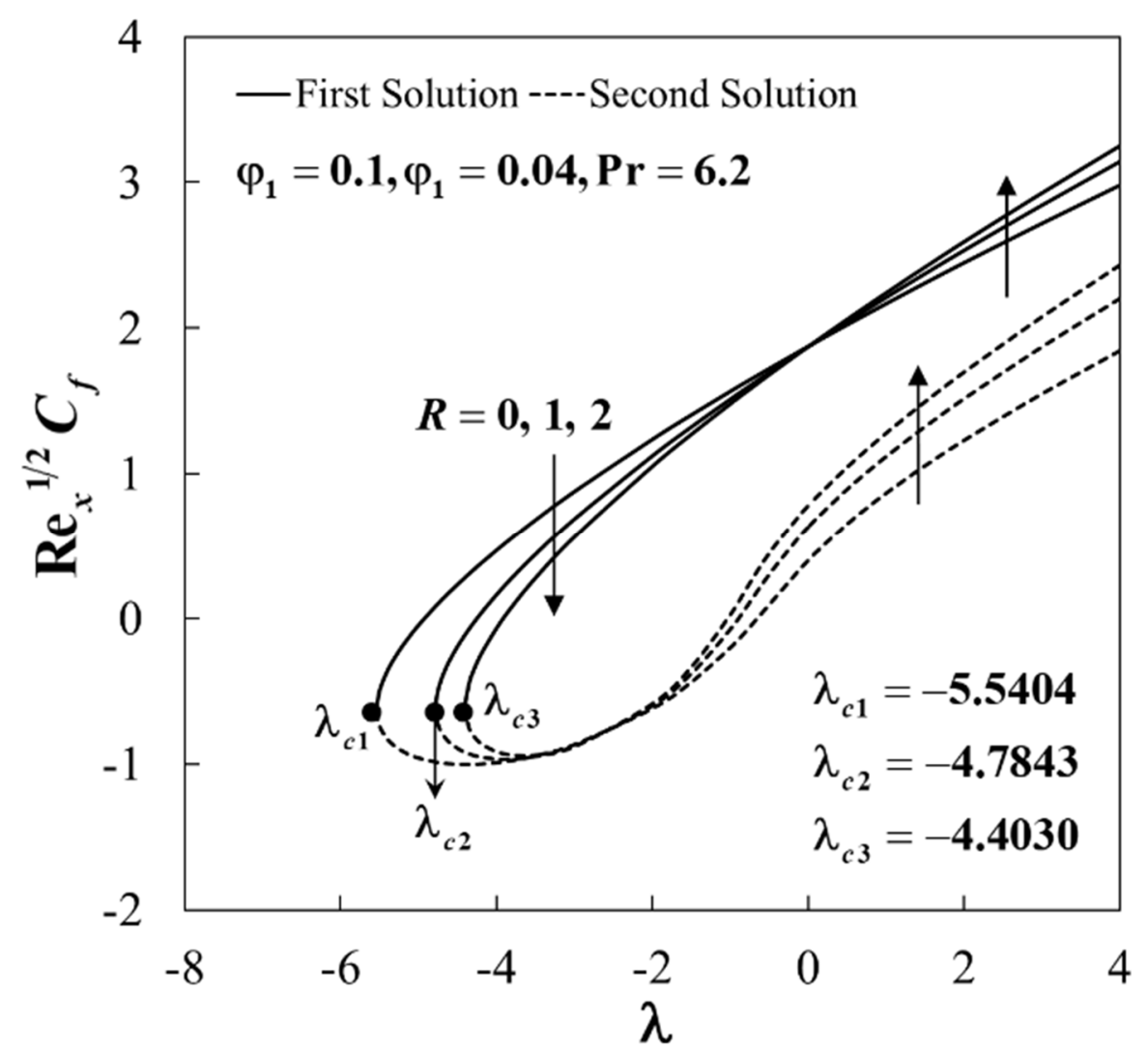

Figure 4. The variations of the skin friction coefficient $\operatorname{Re}_{x}^{1 / 2} C_{f}$ against the mixed convection parameter $\lambda$ for different values of the radiation parameter $R$. 


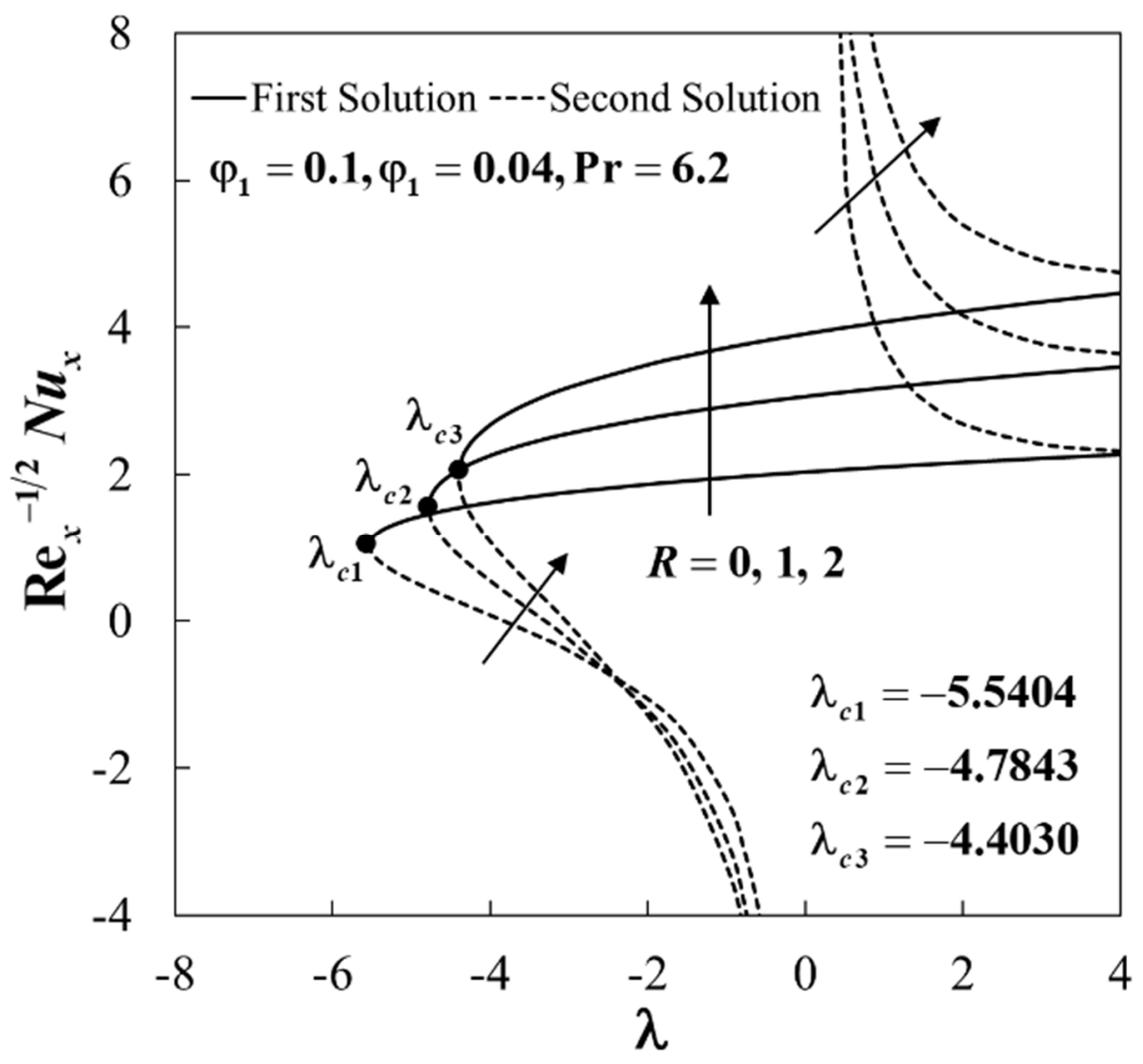

Figure 5. The variations of the local Nusselt number $R e_{x}^{-1 / 2} N u_{x}$ against the mixed convection parameter $\lambda$ for different values of the radiation parameter $R$.

The impact of $\varphi_{2}$ and $R$ on the velocity $f^{\prime}(\eta)$ and the temperature $\theta(\eta)$ profiles for the case of the opposing $(\lambda=-1)$ and assisting $(\lambda=1)$ flows are presented in Figures 6-13. There exist dual solutions for $f^{\prime}(\eta)$ and $\theta(\eta)$ which satisfy the infinity boundary conditions (11) asymptotically. The rising of $\varphi_{2}$ leads to an upsurge in the values of $f^{\prime}(\eta)$ and $\theta(\eta)$ on the first solutions for both cases when $\operatorname{Pr}=6.2, \varphi_{1}=0.1$, and $R=0$ as shown in Figures 6-9. Meanwhile, the velocity $f^{\prime}(\eta)$ decreases when $\lambda=-1$ but increases when $\lambda=1$ on the first solutions for larger values of $R$ when $\operatorname{Pr}=6.2, \varphi_{1}=0.1$, and $\varphi_{2}=0.04$. The effect of $R$ is to increase the temperature $\theta(\eta)$ inside the boundary layer for both cases as displayed in Figures 10-13. The radiation is dominant over conduction for larger values of $R$, causing a rise in the fluid temperature. It is also noticed that the solutions of the lower branch for the velocity have negative values $\left(f^{\prime}(\eta)<0\right)$, which implies that the reverse flow occurs away from the wall, and these behaviors are displayed in Figures 6, 8, 10 and 12. The behaviors of $\theta(\eta)$ with different values of $\varphi_{2}$ and $R$ for both cases are given in Figures 7,9,11 and 13. The overshoot of the temperature $\theta(\eta)$ near the wall is observed when $\lambda=-1$, and $\theta(\eta)<0$ when $\lambda=1$ for the second solution.

The variations of $\gamma$ against $\lambda$ when $\operatorname{Pr}=6.2, \varphi_{1}=0.1, \varphi_{2}=0.04$ and $R=1$ are described in Figure 14. For positive values of $\gamma$, it is noted that $e^{-\gamma \tau} \rightarrow 0$ as time evolves $(\tau \rightarrow \infty)$. In the meantime, for the negative value of $\gamma, e^{-\gamma \tau} \rightarrow \infty$. These behaviors show that the first solution is stable and physically reliable, while the second solution is unstable in the long run. 


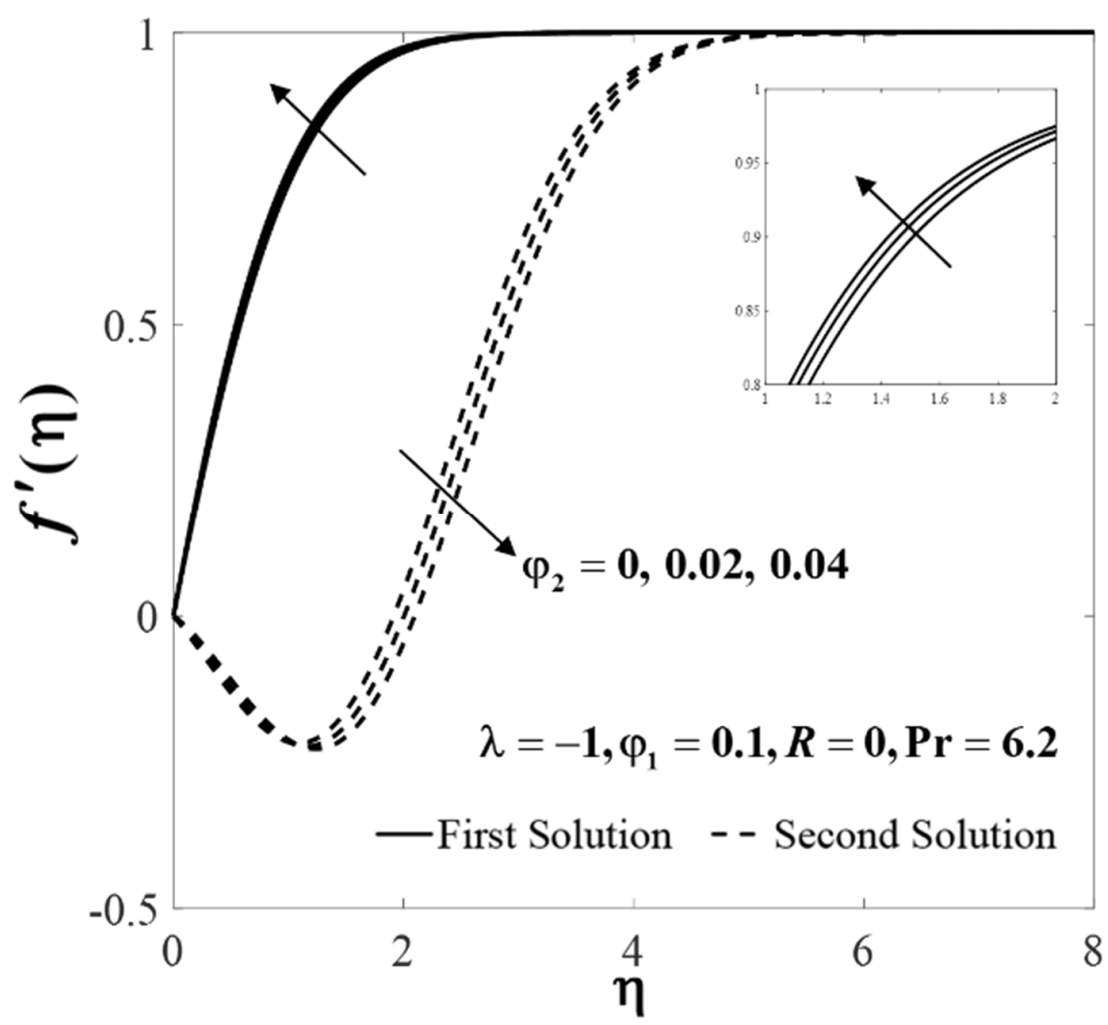

Figure 6. The velocity profiles $f^{\prime}(\eta)$ for different values of the $\mathrm{Cu}$ nanoparticles volume fractions $\varphi_{2}$ when $\lambda=-1$ (opposing flow).

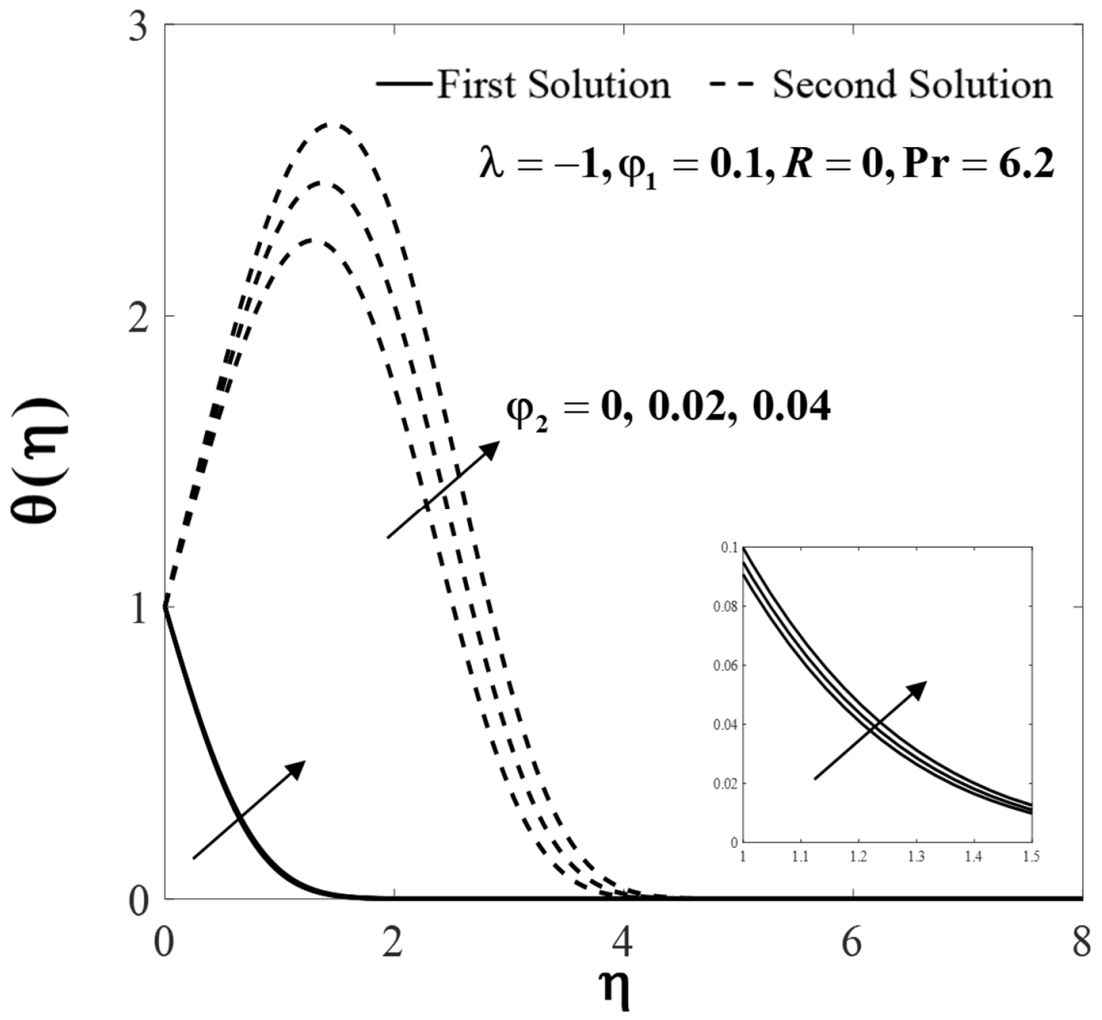

Figure 7. The temperature profiles $\theta(\eta)$ for different values of the $\mathrm{Cu}$ nanoparticles volume fractions $\varphi_{2}$ when $\lambda=-1$ (opposing flow). 


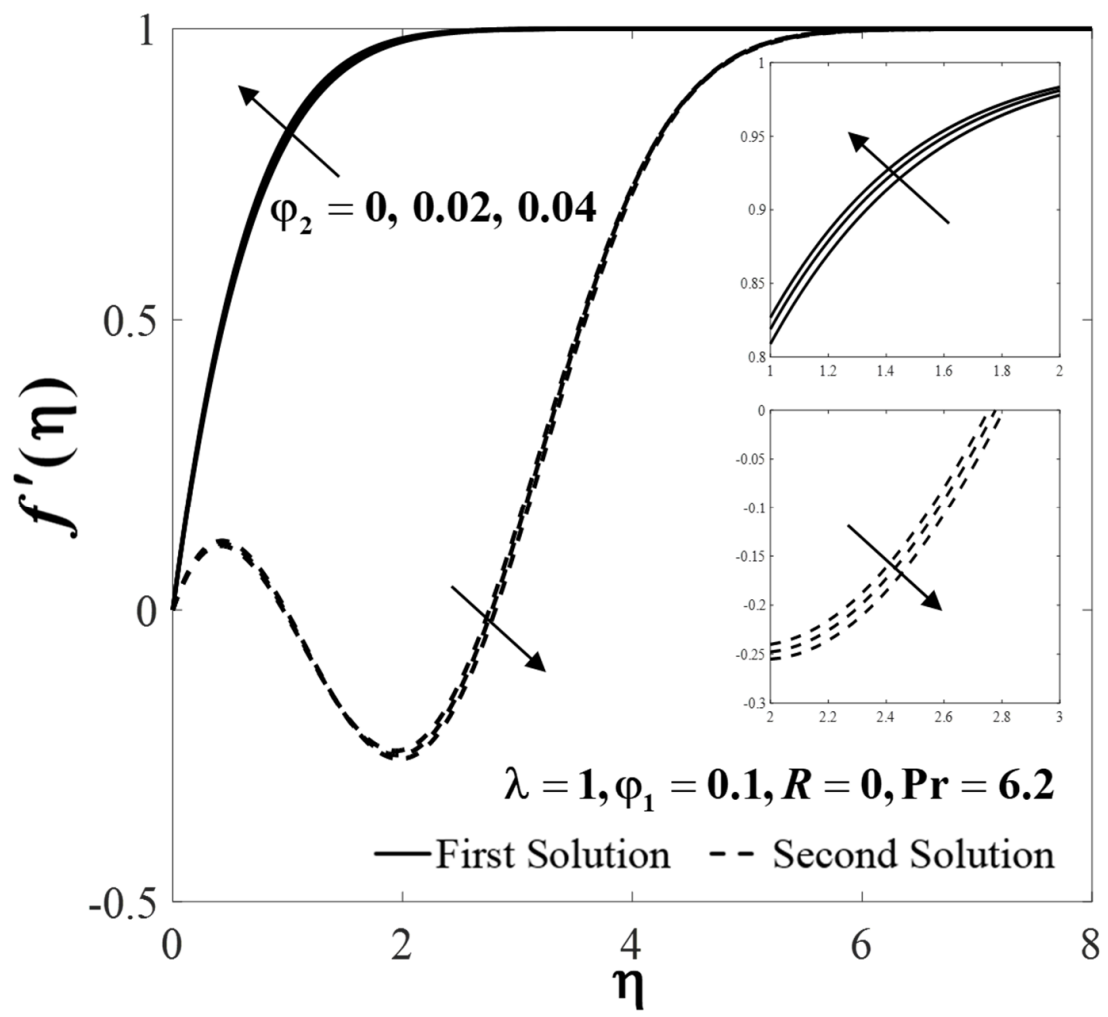

Figure 8. The velocity profiles $f^{\prime}(\eta)$ for different values of the $\mathrm{Cu}$ nanoparticles volume fractions $\varphi_{2}$ when $\lambda=1$ (assisting flow).

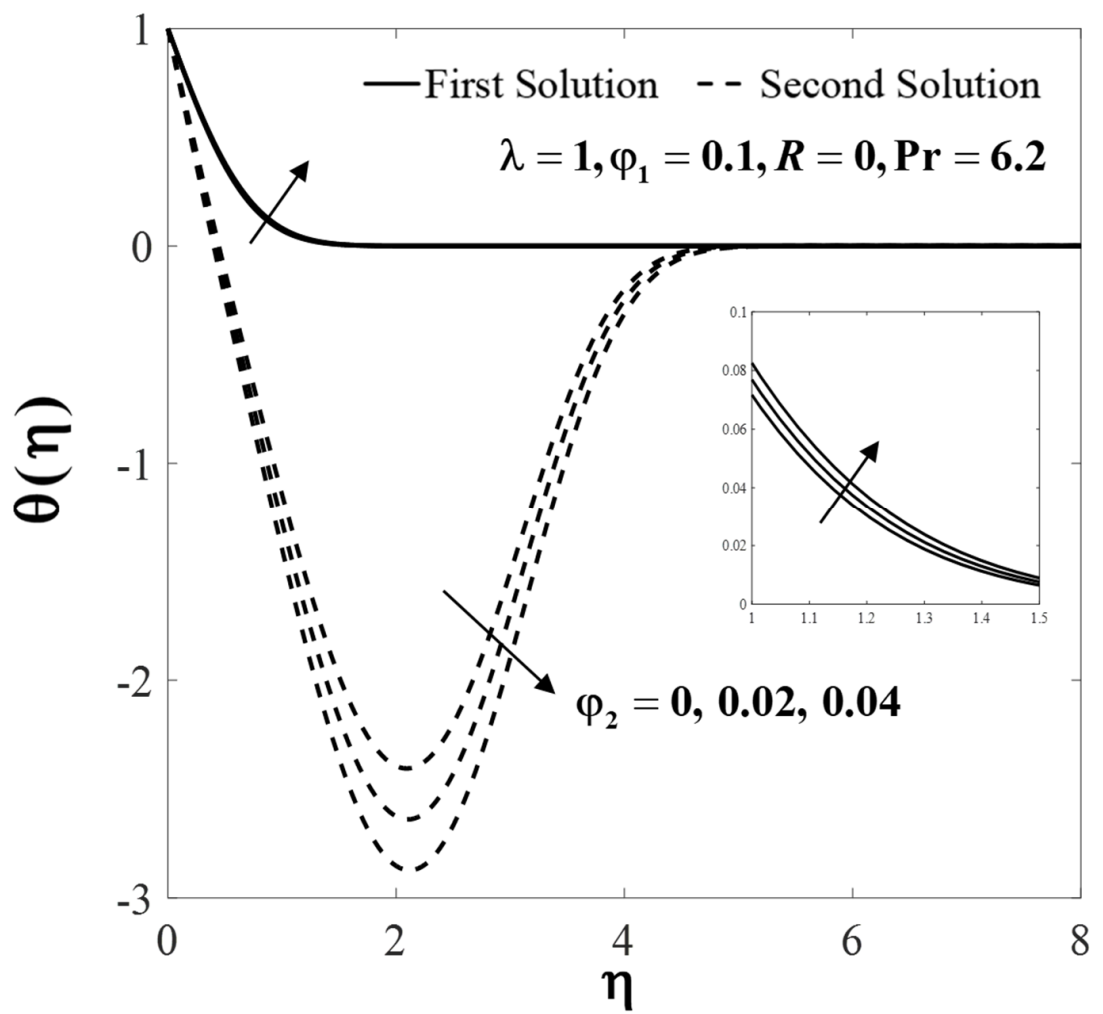

Figure 9. The temperature profiles $\theta(\eta)$ for different values of the $\mathrm{Cu}$ nanoparticle volume fractions $\varphi_{2}$ when $\lambda=1$ (assisting flow). 


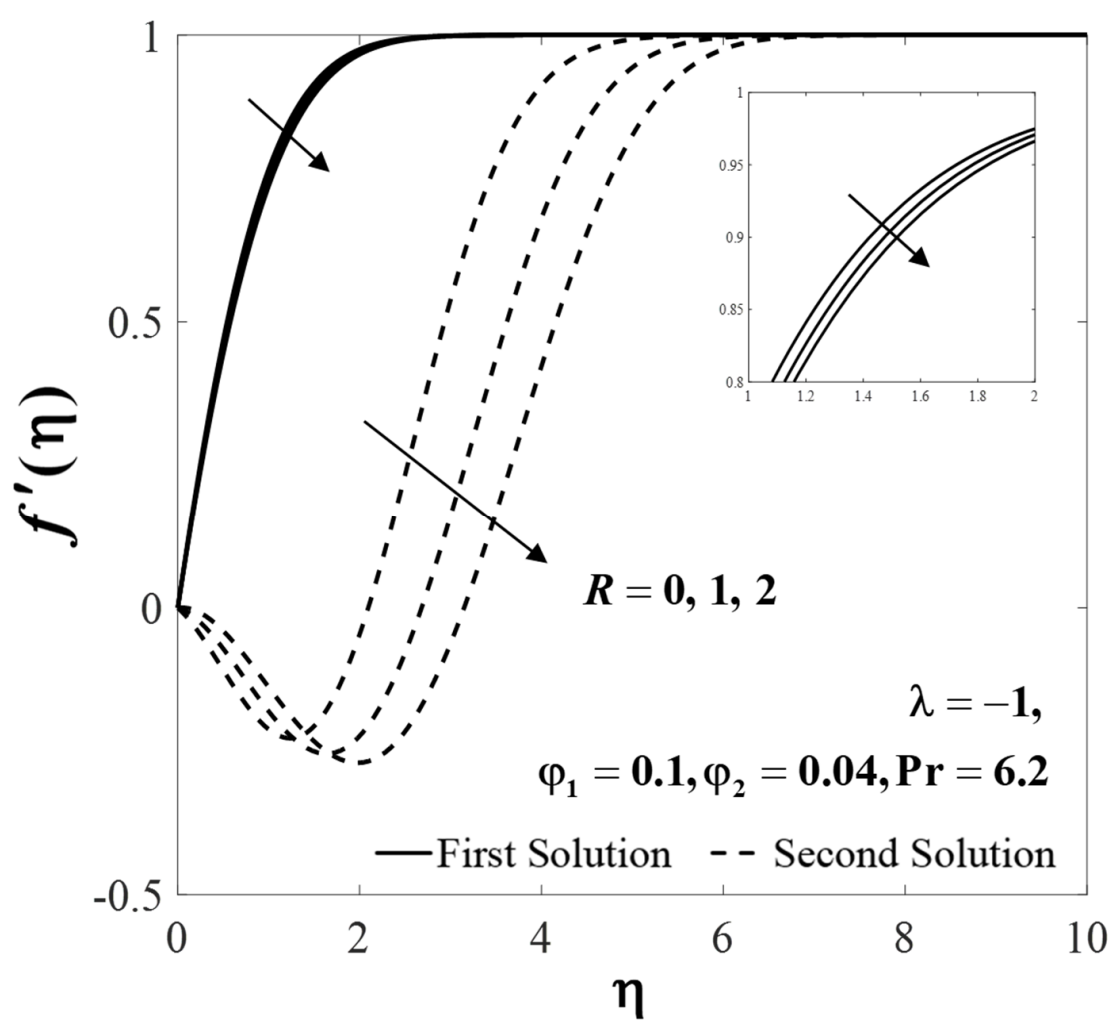

Figure 10. The velocity profiles $f^{\prime}(\eta)$ for different values of the radiation parameter $R$ when $\lambda=-1$ (opposing flow).

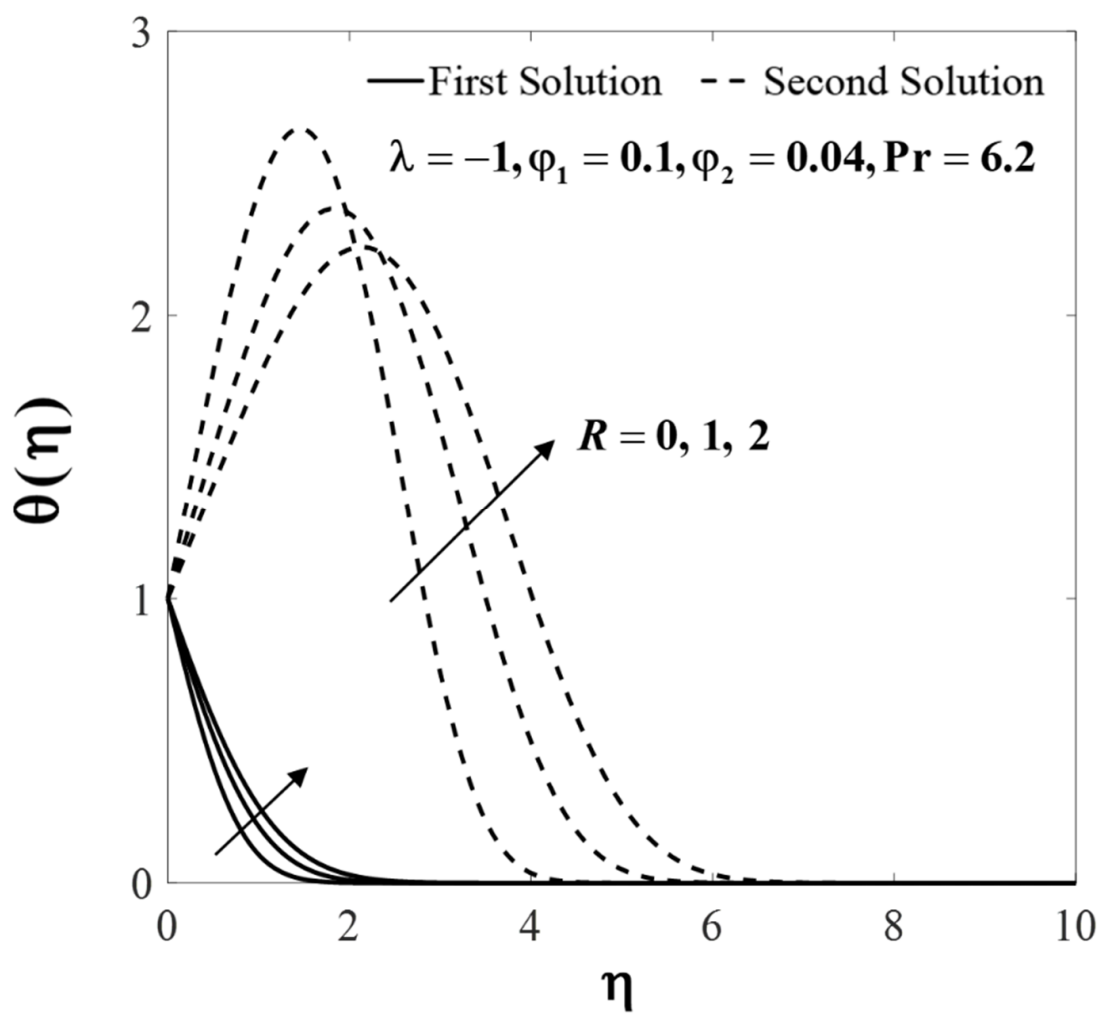

Figure 11. The temperature profiles $\theta(\eta)$ for different values of the radiation parameter $R$ when $\lambda=-1$ (opposing flow). 


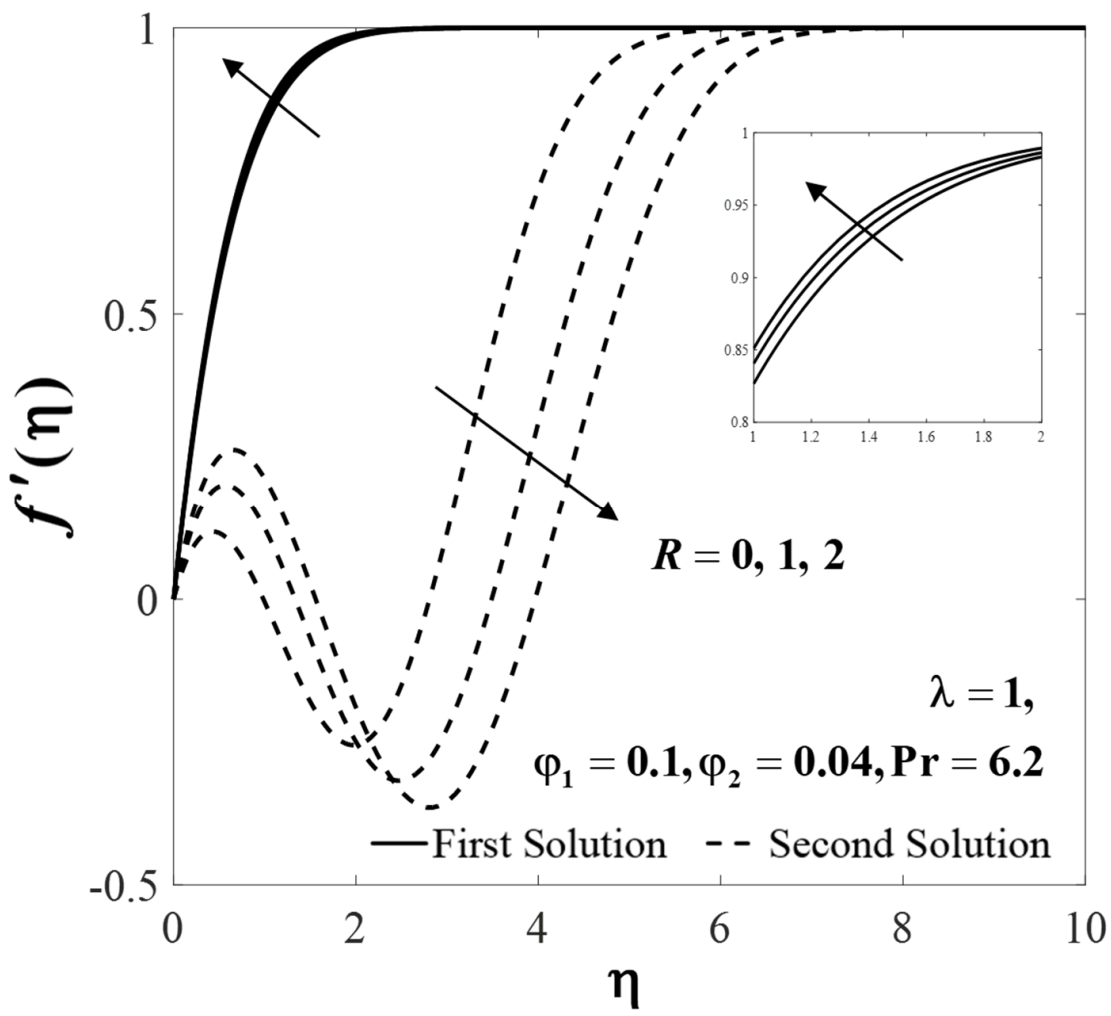

Figure 12. The velocity profiles $f^{\prime}(\eta)$ for different values of the radiation parameter $R$ when $\lambda=1$ (assisting flow).

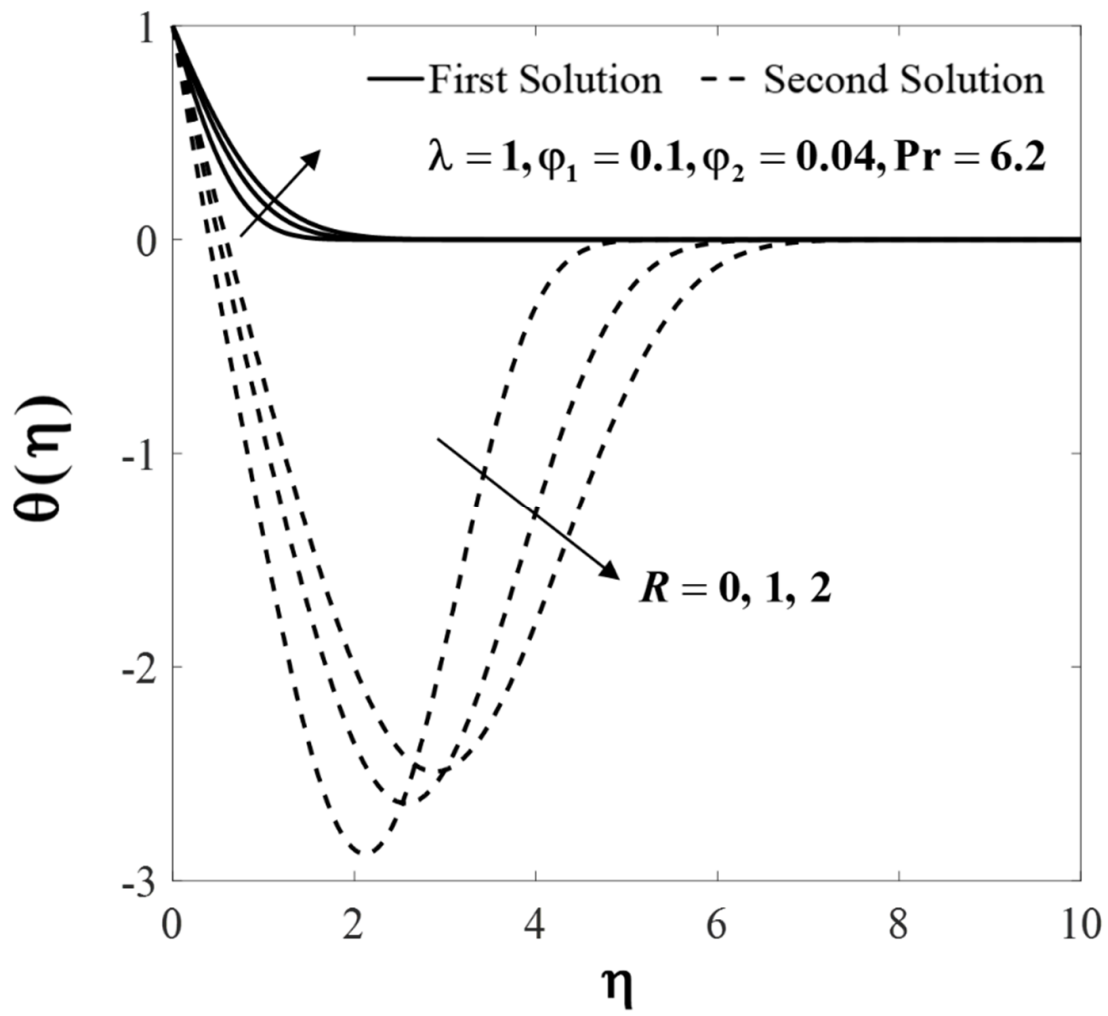

Figure 13. The temperature profiles $\theta(\eta)$ for different values of the radiation parameter $R$ when $\lambda=1$ (assisting flow). 


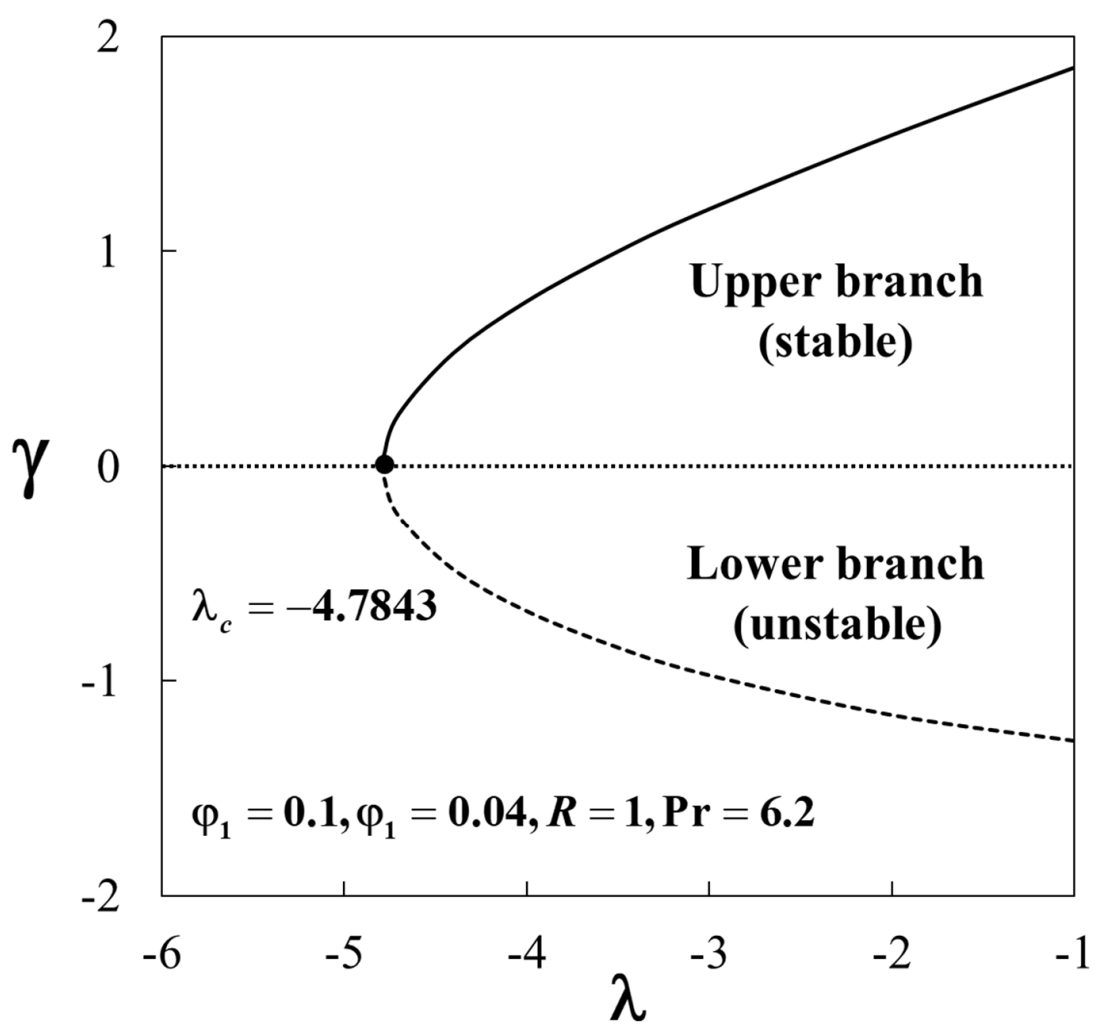

Figure 14. Variations of the smallest eigenvalues $\gamma$ against the mixed convection parameter $\lambda$.

\section{Conclusions}

The stagnation point flow towards a vertical plate in a hybrid nanofluid with thermal radiation was examined in the present paper. Findings revealed that dual solutions appeared for both assisting $(\lambda>0)$ and opposing $(\lambda<0)$ flows. The dual solutions were found for $\lambda>\lambda_{c}$ and no solution for $\lambda<\lambda_{c}$, while the solutions bifurcated at $\lambda=\lambda_{c}$. In addition, the consequence of the copper nanoparticle volume fractions $\varphi_{2}$ is to enhance the skin friction coefficient $R e_{x}^{1 / 2} C_{f}$ and the local Nusselt number $R e_{x}^{-1 / 2} N u_{x}$ for both cases. However, the values of $\operatorname{Re}_{x}^{1 / 2} C_{f}$ decreased for $\lambda<0$, but increased for $\lambda>0$, whereas the values of $R e_{x}^{-1 / 2} N u_{x}$ were intensified for both cases in the presence of the radiation parameter $R$. From these findings, the increments of the local Nusselt number $R e_{x}^{-1 / 2} N u_{x}$ are observed in the range of $8.66 \%$ to $49.63 \%$ for the pertinent physical parameters considered. Besides, we noticed that the domain of the mixed convection parameter $\lambda$ where the dual solutions are in existence decreased for larger $R$. Further, the first solution of the velocity $f^{\prime}(\eta)$ and the temperature $\theta(\eta)$ profiles enlarged with the increase of the copper nanoparticles volume fractions $\varphi_{2}$. Moreover, the effect of the radiation parameter $R$ is to increase the temperature $\theta(\eta)$ inside the boundary layer for both cases. Lastly, it was discovered that between the two solutions, the solution with lower boundary layer thickness is stable and thus physically reliable in the long run.

Author Contributions: Conceptualization, I.P.; funding acquisition, A.I.; methodology, I.W.; Project administration, A.I.; supervision, A.I. and I.P.; validation, I.P.; writing —original draft, I.W.; writingreview and editing, A.I., I.P. All authors have read and agreed to the published version of the manuscript.

Funding: This research was funded by Universiti Kebangsaan Malaysia (Project Code: DIP-2020-001).

Acknowledgments: The authors would like to thank the anonymous reviewers for their constructive comments and suggestions. The financial supports received from the Universiti Kebangsaan Malaysia (Project Code: DIP-2020-001) and the Universiti Teknikal Malaysia Melaka are gratefully acknowledged. 
Conflicts of Interest: The authors declare no conflict of interest.

\section{References}

1. Hiemenz, K. Die Grenzschicht an einem in den gleichförmigen Flüssigkeitsstrom eingetauchten geraden Kreiszylinder. Dinglers Polytech. J. 1911, 326, 321-410.

2. Homann, F. Der Einflub grober Zähigkeit bei der Strömung um den Zylinder und um die Kugel. Z. Angew. Math. Mech. 1936, 16, 153-164. [CrossRef]

3. Chiam, T.C. Stagnation-point flow towards a stretching plate. J. Phys. Soc. Jpn. 1994, 63, 2443-2444. [CrossRef]

4. Merkin, J.H. Mixed convection boundary layer flow on a vertical surface in a saturated porous medium. J. Eng. Math. 1980, 14, 301-313. [CrossRef]

5. Ishak, A.; Nazar, R.; Arifin, N.M.; Pop, I. Dual solutions in mixed convection flow near a stagnation point on a vertical porous plate. Int. J. Therm. Sci. 2008, 47, 417-422. [CrossRef]

6. Subhashini, S.V.; Samuel, N.; Pop, I. Effects of buoyancy assisting and opposing flows on mixed convection boundary layer flow over a permeable vertical surface. Int. Commun. Heat Mass Transf. 2011, 38, 499-503. [CrossRef]

7. Roşca, A.V.; Roşca, N.C.; Pop, I. Note on dual solutions for the mixed convection boundary layer flow close to the lower stagnation point of a horizontal circular cylinder: Case of constant surface heat flux. Sains Malays 2014, 43, 1239-1247.

8. Khashi'ie, N.S.; Arifin, N.M.; Rashidi, M.M.; Hafidzuddin, E.H.; Wahi, N. Magnetohydrodynamics (MHD) stagnation point flow past a shrinking/stretching surface with double stratification effect in a porous medium. J. Therm. Anal. Calorim. 2019, 8, 1-14. [CrossRef]

9. Ali, F.M.; Naganthran, K.; Nazar, R.; Pop, I. MHD mixed convection boundary layer stagnation-point flow on a vertical surface with induced magnetic field. Int. J. Numer. Methods Heat Fluid Flow 2020, 30, 4697-4710. [CrossRef]

10. Choi, S.U.S.; Eastman, J.A. Enhancing Thermal Conductivity of Fluids with Nanoparticles; Argonne National Lab: Lemont, IL, USA 1995; Volume 66, pp. 99-105.

11. Khanafer, K.; Vafai, K.; Lightstone, M. Buoyancy-driven heat transfer enhancement in a two-dimensional enclosure utilizing nanofluids. Int. J. Heat Mass Transf. 2003, 46, 3639-3653. [CrossRef]

12. Tiwari, R.K.; Das, M.K. Heat transfer augmentation in a two-sided lid-driven differentially heated square cavity utilizing nanofluids. Int. J. Heat Mass Transf. 2007, 50, 2002-2018. [CrossRef]

13. Oztop, H.F.; Abu-Nada, E. Numerical study of natural convection in partially heated rectangular enclosures filled with nanofluids. Int. J. Heat Fluid Flow 2008, 29, 1326-1336. [CrossRef]

14. Bachok, N.; Ishak, A.; Pop, I. Stagnation-point flow over a stretching/shrinking sheet in a nanofluid. Nanoscale Res. Lett. 2011, 6, 623. [CrossRef]

15. Yacob, N.A.; Ishak, A.; Pop, I.; Vajravelu, K. Boundary layer flow past a stretching/shrinking surface beneath an external uniform shear flow with a convective surface boundary condition in a nanofluid. Nanoscale Res. Lett. 2011, 6, 314. [CrossRef] [PubMed]

16. Waini, I.; Ishak, A.; Pop, I. Dufour and Soret effects on $\mathrm{Al}_{2} \mathrm{O}_{3}$-water nanofluid flow over a moving thin needle: Tiwari and Das model. Int. J. Numer. Methods Heat Fluid Flow 2020, in press. [CrossRef]

17. Turcu, R.; Darabont, A.; Nan, A.; Aldea, N.; Macovei, D.; Bica, D.; Vekas, L.; Pana, O.; Soran, M.L.; Koos, A.A.; et al. New polypyrrole-multiwall carbon nanotubes hybrid materials. J. Optoelectron. Adv. Mater. 2006, 8, 643-647.

18. Jana, S.; Salehi-Khojin, A.; Zhong, W.H. Enhancement of fluid thermal conductivity by the addition of single and hybrid nano-additives. Thermochim. Acta 2007, 462, 45-55. [CrossRef]

19. Suresh, S.; Venkitaraj, K.P.; Selvakumar, P.; Chandrasekar, M. Synthesis of $\mathrm{Al}_{2} \mathrm{O}_{3}-\mathrm{Cu}$ / water hybrid nanofluids using two step method and its thermo physical properties. Colloids Surfaces A Physicochem. Eng. Asp. 2011, 388, 41-48. [CrossRef]

20. Devi, S.P.A.; Devi, S.S.U. Numerical investigation of hydromagnetic hybrid $\mathrm{Cu}-\mathrm{Al}_{2} \mathrm{O}_{3} /$ water nanofluid flow over a permeable stretching sheet with suction. Int. J. Nonlinear Sci. Numer. Simul. 2016, 17, 249-257. [CrossRef]

21. Waini, I.; Ishak, A.; Pop, I. Mixed convection flow over an exponentially stretching/shrinking vertical surface in a hybrid nanofluid. Alex. Eng. J. 2020, 59, 1881-1891. [CrossRef]

22. Waini, I.; Ishak, A.; Pop, I. Hybrid nanofluid flow past a permeable moving thin needle. Mathematics 2020, 8, 612. [CrossRef]

23. Waini, I.; Ishak, A.; Pop, I. Squeezed hybrid nanofluid flow over a permeable sensor surface. Mathematics 2020, 8, 898. [CrossRef]

24. Waini, I.; Ishak, A.; Pop, I. Hiemenz flow over a shrinking sheet in a hybrid nanofluid. Results Phys. 2020, 19, 103351. [CrossRef]

25. Waini, I.; Ishak, A.; Pop, I. Hybrid nanofluid flow on a shrinking cylinder with prescribed surface heat flux. Int. J. Numer. Methods Heat Fluid Flow 2020, in press. [CrossRef]

26. Waini, I.; Ishak, A.; Pop, I. Melting heat transfer of a hybrid nanofluid flow towards a stagnation point region with second-order slip. Proc. Inst. Mech. Eng. Part E J. Process Mech. Eng. 2020, in press. [CrossRef]

27. Waini, I.; Ishak, A.; Pop, I. Unsteady hybrid nanofluid flow on a stagnation point of a permeable rigid surface. ZAMM Z. Angew. Math. Mech. 2020, in press. [CrossRef]

28. Aly, E.H.; Pop, I. MHD flow and heat transfer over a permeable stretching/shrinking sheet in a hybrid nanofluid with a convective boundary condition. Int. J. Numer. Methods Heat Fluid Flow 2019, 29, 3012-3038. [CrossRef]

29. Khan, U.; Zaib, A.; Khan, I.; Baleanu, D.; Nisar, K.S. Enhanced heat transfer in moderately ionized liquid due to hybrid $\mathrm{MoS}_{2} / \mathrm{SiO}_{2}$ nanofluids exposed by nonlinear radiation: Stability analysis. Crystals 2020, 10, 142. [CrossRef] 
30. Khan, U.; Zaib, A.; Khan, I.; Baleanu, D.; Sherif, E.S.M. Comparative investigation on MHD nonlinear radiative flow through a moving thin needle comprising two hybridized AA7075 and AA7072 alloys nanomaterials through binary chemical reaction with activation energy. J. Mater. Res. Technol. 2020, 9, 3817-3828. [CrossRef]

31. Khashi'ie, N.S.; Arifin, N.M.; Hafidzuddin, E.H.; Wahi, N. Thermally stratified flow of $\mathrm{Cu}_{-} \mathrm{Al}_{2} \mathrm{O}_{3} /$ water hybrid nanofluid past a permeable stretching/shrinking circular cylinder. J. Adv. Res. Fluid Mech. Therm. Sci. 2019, 63, 154-163.

32. Waini, I.; Ishak, A.; Pop, I. Hybrid nanofluid flow towards a stagnation point on a stretching/shrinking cylinder. Sci. Rep. 2020, 10, 9296. [CrossRef] [PubMed]

33. Khashi'ie, N.S.; Arifin, N.M.; Wahi, N.; Pop, I.; Nazar, R.; Hafidzuddin, E.H. Thermal marangoni flow past a permeable stretching/shrinking sheet in a hybrid Cu-Al2O3/water nanofluid. Sains Malays 2020, 49, 211-222. [CrossRef]

34. Zainal, N.A.; Nazar, R.; Naganthran, K.; Pop, I. Unsteady three-dimensional MHD nonaxisymmetric Homann stagnation point flow of a hybrid nanofluid with stability analysis. Mathematics 2020, 8, 784. [CrossRef]

35. Zainal, N.A.; Nazar, R.; Naganthran, K.; Pop, I. Impact of anisotropic slip on the stagnation-point flow past a stretching/shrinking surface of the $\mathrm{Al}_{2} \mathrm{O}_{3}-\mathrm{Cu} / \mathrm{H}_{2} \mathrm{O}$ hybrid nanofluid. Appl. Math. Mech. 2020, 41, 1401-1416. [CrossRef]

36. Sarkar, J.; Ghosh, P.; Adil, A. A review on hybrid nanofluids: Recent research, development and applications. Renew. Sustain. Energy Rev. 2015, 43, 164-177. [CrossRef]

37. Sidik, N.A.C.; Adamu, I.M.; Jamil, M.M.; Kefayati, G.H.R.; Mamat, R.; Najafi, G. Recent progress on hybrid nanofluids in heat transfer applications: A comprehensive review. Int. Commun. Heat Mass Transf. 2016, 78, 68-79. [CrossRef]

38. Babu, J.A.R.; Kumar, K.K.; Rao, S.S. State-of-art review on hybrid nanofluids. Renew. Sustain. Energy Rev. 2017, 77, 551-565. [CrossRef]

39. Sajid, M.U.; Ali, H.M. Thermal conductivity of hybrid nanofluids: A critical review. Int. J. Heat Mass Transf. 2018, 126, 211-234. [CrossRef]

40. Huminic, G.; Huminic, A. Entropy generation of nanofluid and hybrid nanofluid flow in thermal systems: A review. J. Mol. Liq. 2020, 302, 112533. [CrossRef]

41. Yang, L.; Ji, W.; Mao, M.; Huang, J. An updated review on the properties, fabrication and application of hybrid-nanofluids along with their environmental effects. J. Clean. Prod. 2020, 257, 120408. [CrossRef]

42. Rosseland, S. Astrophysik und Atom-Theoretische Grundlagen; Springer: Berlin/Heidelberg, Germany, 1931.

43. Cortell, R. Heat and fluid flow due to non-linearly stretching surfaces. Appl. Math. Comput. 2011, 217, 7564-7572. [CrossRef]

44. Merkin, J.H. On dual solutions occurring in mixed convection in a porous medium. J. Eng. Math. 1986, 20, 171-179. [CrossRef]

45. Weidman, P.D.; Kubitschek, D.G.; Davis, A.M.J. The effect of transpiration on self-similar boundary layer flow over moving surfaces. Int. J. Eng. Sci. 2006, 44, 730-737. [CrossRef]

46. Harris, S.D.; Ingham, D.B.; Pop, I. Mixed convection boundary-layer flow near the stagnation point on a vertical surface in a porous medium: Brinkman model with slip. Transp. Porous Media 2009, 77, 267-285. [CrossRef]

47. Shampine, L.F.; Gladwell, I.; Thompson, S. Solving ODEs with MATLAB.; Cambridge University Press: Cambridge, UK, 2003. 